\title{
Numerical Investigations on GFRP beam with Delaminations
}

\author{
T. G. Sreekanth ${ }^{\mathrm{a}}$, S.Sureshkumar ${ }^{\mathrm{b}}$, H. MeenakshiSundaram ${ }^{\mathrm{b}}$, H. Sameer Lukman ${ }^{\mathrm{b}}, \mathrm{R}$. \\ Anishkrishnan ${ }^{\mathrm{b}}$ \\ \{stg.prod@psgtech.ac.in ${ }^{\mathrm{a}}$, sureshkumar15p652@ gmail.com ${ }^{\mathrm{b}}$, sundarkrish1206@gmail.com ${ }^{\mathrm{b}}$, \\ kameez2000@gmail.com ${ }^{\mathrm{b}}$, message.krish44@gmail.com ${ }^{\mathrm{b}}$ \} \\ aAssistant Professor, Department of Production Engineering, PSG College of Technology, \\ Coimbatore, ${ }^{\mathrm{b}}$ Students, Department of Production engineering, PSG College of Technology, Coimbatore
}

\begin{abstract}
Usage of composites have rapidly increased in various applications likeaerospace, marine, automotive; because of their superior fatigue properties, good strength to weight ratio, corrosion resistance, etc. This work focus on Glass fibre Reinforced Polymer (GFRP) composite with epoxy as matrix, as it is the most commonly usedfibre with high strength and low cost. Numerical analysis on GFRP samples with and without delaminations having same stacking sequence and eight layers were done using ANSYS mechanical APDL software. It is observed that Natural Frequencies is varying according to changes in delaminations parameters.
\end{abstract}

Keywords: Delamination,Natural Frequency, GFRP.

\section{Introduction}

Polymer Matrix Composite (PMC) consists of Polymer resin as matrix reinforced with the fibres such as glass, carbon and aramid. PMC has high strength and less weight. It has advantages such as high fatigue characteristics and ease of fabrication and less cost. The matrix will determines the service temperature, as it normally melts or degrades at lower temperatures compare to the fibre reinforcements. The resins used are either thermosetting or thermoplastic polymers. Some of the Thermoplastics are polyethylene, polystyrene, Nylon 66 and some of the Thermoset polymers are epoxy, polyester, phenol-formaldehyde. For this work, Glass fibreis considered with epoxy as matrix material.

Delamination is the separation of adjacent layers of composite laminates due to weakening of interface layer. It is a failure mode where a material separate into separate layers. Delamination eventually leads to the failure of the composite material. Delamination can be caused by several factors like contrary materials blended together, usage of mould release agent in large quantity, low melting temperature in the cavity, high moisture content, inappropriate laying of laminae, inadequate curing temperature, pressure and time of curing, inclusions, etc. Also due to Action of load during service condition, delaminations may occur and propogate. Cracks also slowly propogate and finally leads to delaminations (1).

In laminated composite material, the adhesion connecting layers often fails resulting the separation of layers. For example, in fibre reinforced plastics, sheets of high strength reinforcement like carbon fibre or glass fibre are bound together by a weaker polymer matrix such as epoxies. Delamination reduces the strength and stiffness of the structure and it causes 
stress concentration in load bearing plies, which in turn causes a local instability which may further leads to delamination growth. Unidirectional layer stacking may be an ideal laminate for unidirectional loads. But for complex loading and stiffness requirements, it is not sufficient and it can be solved by creation of a laminate with layers stacked at different angles. Delamination may leads to loss of life and money during the service level of the composite structure. It is a critical failure mode in fibre-reinforced composites which causes the material fracture into layers, which can cause severe accidents during the working conditions of the composite structures like parts used in the aerospace applications (2).

Muhammad Imran et al.investigated the effect of Delamination size and Stacking sequence for the Carbon Fibre Reinforced Polymer Composite. They used both Finite element approach and Analytical approach to investigate the effect of delaminations (3). Song Zhou et al. did experimental and Finite element analysis of carbon fibre composite with three different stacking sequences. They recorded the failure mode and delamination in each specimen for different layup sequence on failure mechanism (4). Swapnil et al.studied about the Vibration Analysis of Composite plate where he found the natural frequencies for the different fibre orientation. The dimension of the Composite beam to be considered for this research work isfinalized according to the ASTM D3039 standard (5).

Pushparajet al.did research on the vibration Analysis of laminated composite structures using numerical method to figure out the vibration parameters of a Glass fibre Reinforced Polymer Composite and Carbon Fibre Reinforced Polymer Composite (6).E.Zumelzu et al. did study of vibrationalparameters on the viscoelastic coating on the steel layer of a metal - polymer composite, with replicatedsituation of the moving of food containers (7). Sharayuet al. studied about the consequence of delamination on vibration parameters of composite structure to arrive mode shapes and modal frequencies at different location of delaminations (8).

The methodology followed for the present work involves selection of materials, selection of staking sequence, selection of fabrication methods and the selection of beam dimensions.Polymer matrix composite (PMC) have polymer matrix as resin with fibres as reinforcement medium. It is used in greatest diversity of composite applications and can be used in large quantities at room temperature properties with easiness of fabrication and cost. There are three types of PMC depends on the reinforcement material like glass, carbon and aramid. Glass is well-liked as fibre reinforcement for several reasons such as it is effortlessly drawn in to elevated strengths from the molten state, it is fairly strong and with high specific strength, most frequentlyused fibre in Polymer Matrix Composite, high Ultimate Tensile Strength, low cost, high chemical stability and good insulating properties.

Epoxy resin is the widely used PMC matrix and more than two thirds of the PMCs used in aerospace application are epoxy based. It has low viscosity,high strength and low flow rates.

\section{Selection Of Stacking Sequence And Dimensions}

Stacking sequence was selected according to the failure strength of the different lay up sequence fromMuhammad Imran et al.as they analyzedthe influence of different layup sequence on composite material failure mechanisms. 


\begin{tabular}{ll} 
Layup sequence & Strength (MPa) \\
\hline$\left[45_{3} / \mathrm{O}_{3} /-45_{3} / 90_{3}\right]_{\mathrm{s}}$ & 164.6 \\
{$[45 / 90 /-45 / 0]_{3 \mathrm{~s}}$} & 231.0 \\
{$\left[45_{3} / 90_{3} /-45_{3} / \mathrm{O}_{3}\right]_{\mathrm{s}}$} & 204.6
\end{tabular}

Figure 4. Failure strength of each laminate

The layup sequence with $231 \mathrm{MPa}$ was selected for the further study and analysis as it has the highest failure strength among three layup sequences.

Dimension of the composite beam is decided based on ASTM -D3039. It is used to determine the force required to fracture a Polymer composite and the level to which the specimen elongates to that breaking point. $250 \mathrm{~mm}$ length and $25 \mathrm{~mm}$ wide and thickness depend on the number of plies. The purpose of the study is not to identify the failure strength of the polymer matrix composite, and it is to identify the natural frequency at different modes of the polymer matrix composite.

\section{Modal Analysis}

ANSYS Parametric Design Language is a dominant scripting language which allows parameterizing the model and simplifying common tasks. Modal analysis is the learning of the dynamic characteristics of systems in the frequency domain. It can be used to undestand how the specimen will react to any excitation at any frequency if the excitation frequency is closer to any of its natural modes. Thus modal analysis helps toidentify the frequencies of free vibrationand shapes of deformation of the structure.
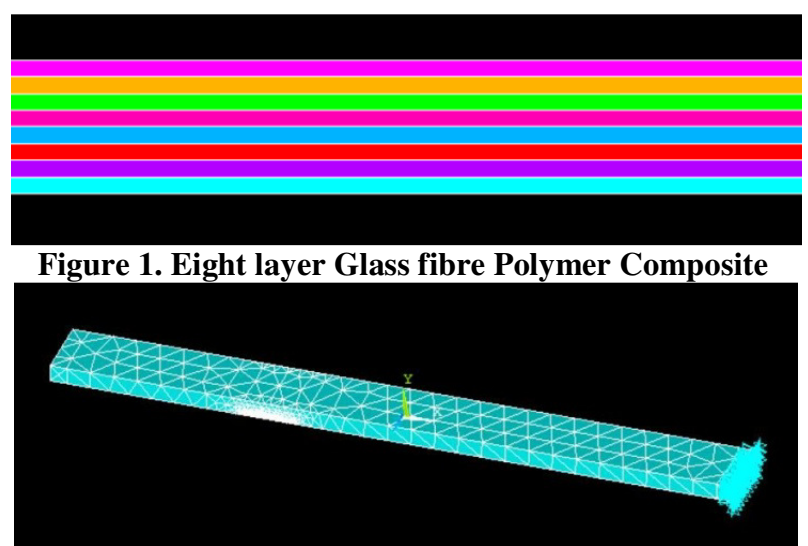

Figure 2. Meshing and arresting of one side

Initially analysis were carried out for the Polymer matrix composite without delamination.8-layer GFRP Composite is modeled in the ANSYS mechanical APDL software and the dimensions of the beam is asperASTM -D3039as shown in figure 1. Tthe stacking sequence of the beam is ( 0 degree/ 90 degree/ 0 degree/ 90 degree)symmetrical. Initially, the model of the plate was created in the ANSYS mechanical APDL software.In the preprocessor, the element type, input density, elastic modulus, shear modulus, poisson's ratio, the thickness of each and every stacking layer is given.All 8 layers are separated in to different 
volumes and the contact bonding is created between each and every interface layers using its node numbers. The meshing is completed and one side is made fixed as cantilever beam as shown in figure 2. Natural frequencies of beam without delaminations are shown in table 1.

Table 1 Natural frequency of beam without delamination

\begin{tabular}{|l|c|}
\hline Mode & Natural Frequency $(\mathbf{H z})$ \\
\hline $\mathbf{1}$ & 39.652 \\
\hline $\mathbf{2}$ & 290.74 \\
\hline $\mathbf{3}$ & 769.97 \\
\hline $\mathbf{4}$ & 1606.2 \\
\hline
\end{tabular}

\section{Modal analysis of beams with delamination}

The same analysis procedure is carried out for compsosite beams with delaminations located at various distances from free end of the cantilever beam. Creation of delaminations between layers was carried out by not bonding the layer areas having delaminations.Comparison of first natural frequenciesof delaminations at the location $50 \mathrm{~mm}$ from free end is shown in figure 3. Delamination size $\left(A=100 \mathrm{~mm}^{2}, B=200 \mathrm{~mm}^{2}, C=300\right.$ $\mathrm{mm}^{2}, \mathrm{D}=400 \mathrm{~mm}^{2}$ and $\mathrm{E}=500 \mathrm{~mm}^{2}$ ) is plotted in $\mathrm{x}$ axis and natural frequencies are plotted in $\mathrm{y}$ axis. $\mathrm{Z}$ is the distance from bottom of the beam, indicating the layer in which delaminations is considered. It is clear from the graph that natural frequency is reducing with increase in delamination areas.

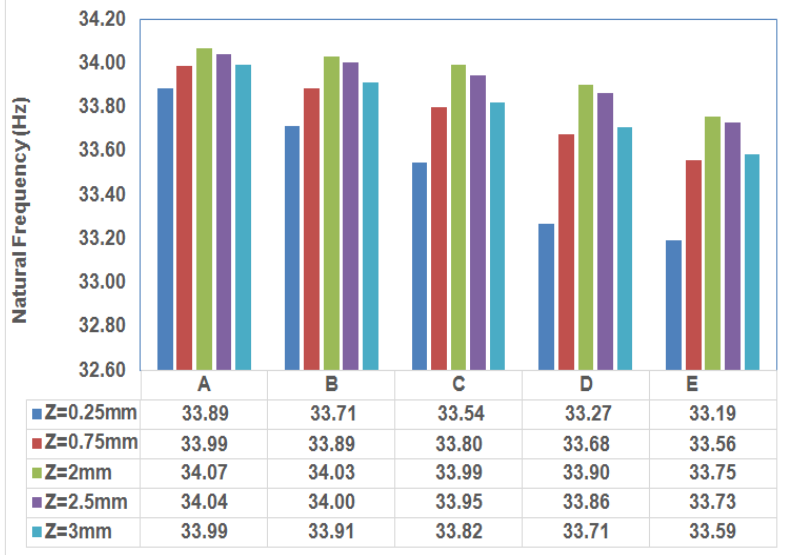

Figure 3 Comparison of first Natural frequency of different delaminationsscenarios at the location $50 \mathrm{~mm}$ from free end

Similar analyses were performed for delaminations at various locations. Comparison of first natural frequencies of delaminations at the location $80 \mathrm{~mm}, 110 \mathrm{~mm}$ and $130 \mathrm{~mm}$ from free end is shown in figure 4, 5 and 6 respectively. Analyzing the figures, it is clear that the first natural frequency is maximum when delamination is at middle layer. That is first natural frequency is lesser when delaminations is at top or bottom layers. Also it is clear from all figures that first natural frequency is high if delaminations are closer to fixed end of beam. 
That is, natural frequency of a beam with delaminations near free end will be lower compared to natural frequency of beam with same delaminations area near fixed end.

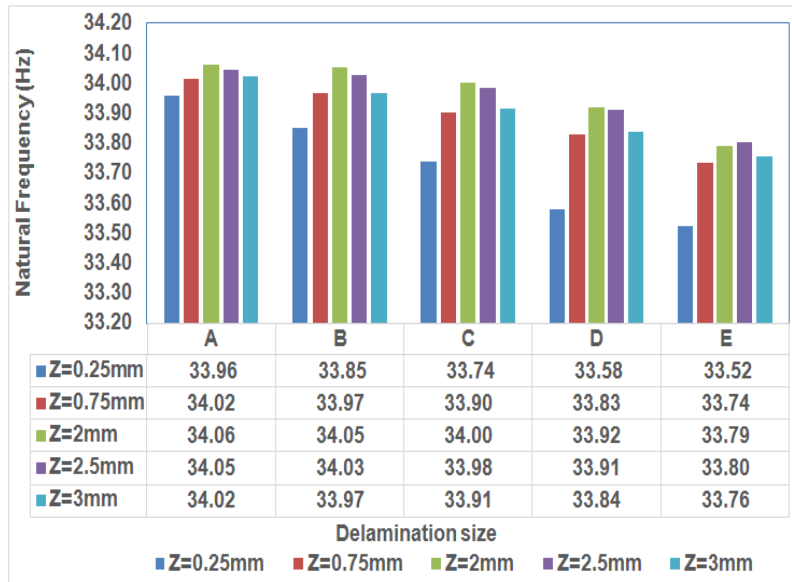

Figure 4 Comparison of first Natural frequency of different delaminationsscenarios at the location $80 \mathrm{~mm}$ from free end

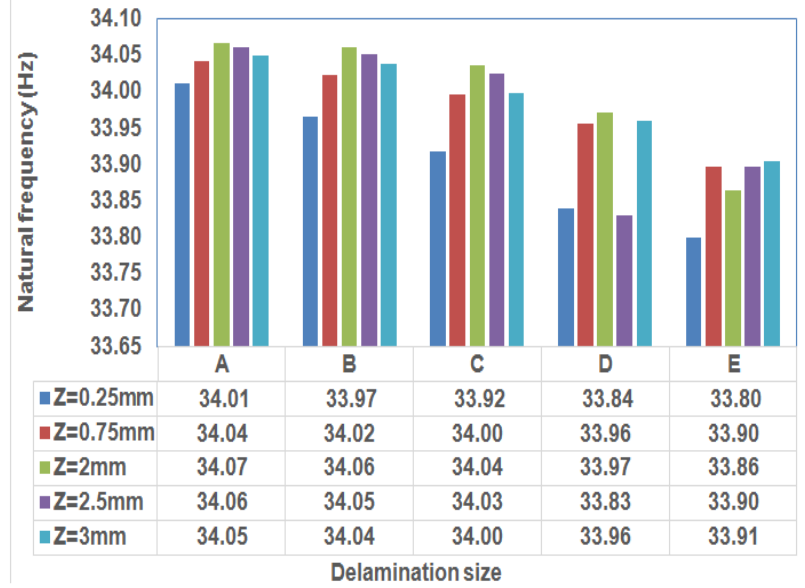

Figure 5Comparison of first Natural frequency of different delaminationsscenarios at the location $110 \mathrm{~mm}$ from free end 


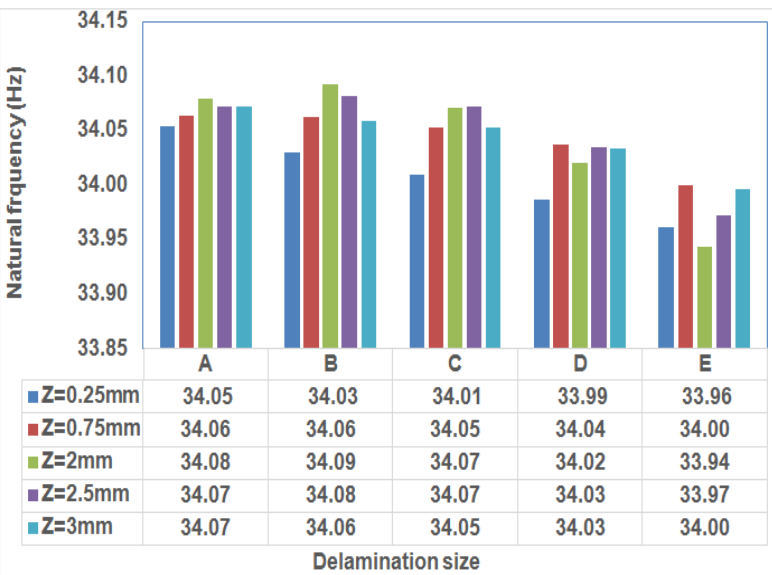

Figure 6Comparison of first Natural frequency of different delaminations scenarios at the location $130 \mathrm{~mm}$ from free end

\section{Conclusion}

In the present study, modal analysis of the 8 layer GFRP beam is performed by using the ANSYS mechanical APDL software to find out the natural frequencies. The approach followed here aims finding how the natural frequencies vary with different location and size of the delamination. It is observed that the natural frequency is reducing with increase in delamination areas. It is also observed that the first natural frequency is maximum when delamination is at middle layer and first natural frequency is high if delaminations are closer to fixed end of beam. All these points indicate that vibration parameter like natural frequency can be best used for researches in the area of delaminations in composite structures.

\section{References}

[1] Senthilkumar, M, Sreekanth, TG \&Manikanta Reddy, S 2020, 'Nondestructive health monitoring techniques for composite materials: A review', Polymers and Polymer Composites, vol. 29, no. 5, pp. 528-540. ISSN: 0967-3911

[2] Sreekanth, TG, Senthilkumar, M \& Reddy, SM 2021, 'Fatigue Life Evaluation of Delaminated GFRP Laminates Using Artificial Neural Networks', Transactions of the Indian Institute of Metals, vol. 74, no. 6, pp. 1439-1445. ISSN: 0972-2815

[3] Muhammad Imran, Rafiullah Khan, Saeed Badshah. "Investigating the effect of delamination size, stacking sequence and boundary conditions on the vibration properties of carbon fibre reinforced polymer composite". Materials Research.2019.

[4] Song Zhou, Jinhua Zhang, Yi Sun, Kun Tian. "Experimental and numerical investigation of open hole carbon fibre composite laminates under compression with three different stacking sequences". Journal of materials research and technology.2019.

[5] Swapnil Sanjay Chavan. "Study on vibration analysis of composite plate". International conference on multidisciplinary research and practice. Volume I issue VIII.

[6] PushparajPingulkar and Suresha B. "Free vibration analysis of composite plates using finite element method". Polymers and Polymer composite, Vol.24, No.7.2016. 
[7] E. Zumelzu, R. Pereira, J. P. Arenas, F. Rull, R. Silva. "Influence of Vibrations on Interface Delamination in Metal-Polymer Composites". Journal of Applied Polymer Science, Vol. 125, 97103 (2012).

[8] Sharayu U. Ratnaparkhi, S.S. Sarnobat. "Vibration Analysis of Composite plate".International Journal of Modern Engineering Research (IJMER) .Vol.3, Issue.1, Jan-Feb. 2013 pp-377-380

[9] D. S. Vijayan, A. Mohan, J. J. Daniel, V. Gokulnath, B. Saravanan, and P. D. Kumar, "Experimental Investigation on the Ecofriendly External Wrapping of Glass Fiber Reinforced Polymer in Concrete Columns," vol. 2021, 2021.

[10] LavanyaPrabha, S., Gopalakrishnan, M., Neelamegam, M., Development of high-strength nanocementitious composites using copper slag, ACI Materials Journal , 2020, 117(4), pp. 37-46. 